\title{
Deontological Preparedness of the Teacher as a Guarantee of Psychological Comfort in the Classroom
}

\author{
Galiyabanu Kertayeva \\ Pavlodar State University
}

\begin{abstract}
The article focuses on the study of the concept "deontological preparedness", which is one of the main concepts of Pedagogical Deontology. Pedagogical Deontology studies a teacher as an educator. It focuses on the professional development of a teacher. The concept "deontological preparedness" serves as an indicator of the development of teachers' professional competence, value orientations, knowledge of the norms of pedagogical ethics. The author examines different approaches to research teachers' professional preparedness and analyzes various interpretations of the concept "deontological preparedness".
\end{abstract}

\section{Introduction}

Sociohistorical context influences the world education systems and formulates requirements to teachers' activity and their professional qualities. Present day political, economic and social relations along with national traditions transform the existing education systems. Many world education systems have been experiencing reformation and modernization. Modern educational policy demands new approaches to training of pedagogical staff. The term "deontological preparedness" is singled out in Pedagogical Deontology to denote a complex of significant professional qualities needed by new generation teachers.

\section{The Concept "Deontological Preparedness" in Pedagogy}

In modern conditions of social change, when a person is not a passive object of the influence of environment, but an active being, the effectiveness of the educating process depends not only on the external conditions of education - teachers' skills, rational construction of the curriculum, textbooks, teaching materials, teaching methods, equipment, but also on its internal state, its self-organization, and psychological environment.

L.T.Ohitina in the book "Psychological Foundations of the Lesson" is writing: "In lesson organization there should be distinguished the teacher's self-organization and organization of students' cognitive activity" [1]. If the teacher involves learners in various activities, develops useful skills in and outside the classroom, discusses various issues, helps to cope with difficulties, becomes a model for the learners, there established psychological contact, which, in our opinion, creates affective environment conducive to learning.

There is, however, a significant contrast of opinions between students and their teachers in the evaluation of the same psychological situations. T.N. Malkovsky (an educator, who studied the relationship of children and adults) conducted a survey of teachers and their students to find out whether, in their opinion, psychological contact was or was not established. The difference between the responses of teachers and students was overwhelming. "The contact is established" answered $73 \%$ of teachers and $18 \%$ of students; "partially established", noted $6 \%$ of teachers and $47 \%$ of the students, "there is no contact", stated $3 \%$ of teachers and $28 \%$ of students.

Such contrast in teachers and learners' responses can probably be explained by the fact that the teachers and students have different understandings of the word "contact". Teachers have in mind just a normal psychological climate, which supports the educational process, while the students understand it as empathy, emotional warmth, and psychological intimacy, which in reality are quite rare. And, while the consciousness of the students is illusory in its maximalist way, as their requirements are not met, the consciousness of adults is illusory in a different way: they overestimate the extent of their closeness to students and thus the extent of their influence on them.

Ozhegov's dictionary of the Russian language gives the following interpretation of the words "contact" and "mind": contact - communication, coordination, close contacts; mind - set of spiritual experiences, as reflected in the consciousness of objective reality"[2]. Hence, psychological contact is such a connection, which corresponds to the highest consistency of spiritual experiences, when seen through, combining communication, and attunement.

To create such a contact a teacher should be able to adequately evaluate the behavior of children in any contact situation. A teacher should be able to determine their internal state by external features. 
This ability should be expressed in the ability to carefully analyze expression of the eyes, movement, facial expression, gestures, and other "identification signals". However, the question here is what can serve as criteria in the assessment of the correctness of the teacher's conclusions? Is adequate understanding of the inner state of the students by analyzing external expression guaranteed? An extract from an old Chinese fairy-tale gives a clear answer to these questions. "Two friends Chang- chieh and Guichieh stood on the bridge and looked at the frolicking fish. Look how happy they are, - said Chung-chieh. But you are not a fish - said Gui- chieh, - how can you claim that they are happy. Chung-chieh said: I know this from my own experience as water makes me happy. The extract shows that in order to adequately understand the emotional state of the children, teachers should:

- first, be able to (and learn) to put themselves in the position of a child, remember their own state in similar situations;

- $\quad$ secondly, constantly enrich their own world of feelings and analyze them. The brighter, deeper, more deliberate their feelings are, the more likely that they will understand the child's feelings. This advice, of course does not exclude the role of expertise in child psychology.

Belgian psychologists M. Rober and F. Tillman, in their book "The Psychology of the Individual and the Group", put it the following way: "If people treat the child with understanding and care, then needs of social character are shaped and developed. He will be open, friendly and altruistic. There will be no grounds for the development of aggression. He will also not have to suppress his hostile impulses against his environment. If the people who surround the child treat him in a rude way, showing no love, that will result in the child's aggressive actions and the development of antisocial needs. The child will become closed and suppressed, or demonstrate the spirit of independence and adventure" [3].

The first case is a premise for the establishment of psychological contact, the second one leads to psychological conflict, and therefore to the neuroses and psychosomatic illnesses. Therefore, in the name of the basic principle of pedagogical deontology "Do no harm!" every teacher should strive to establish positive classroom atmosphere and create the situation of psychological comfort.

Psychological components of teacher's selforganization in the classroom are represented by teacher's creative operational state and psychological contact with the class". V. Kan-Kalik in his publication "Pedagogical Communication of Innovative Teachers" is writing that classroom communication of a famous pedagogue V. Shatalov creates a situation of psychological comfort, a rare opportunity for cognitive emotional emancipation of the children, when everyone has the opportunity to express himself [4]. Once, during one of the meetings, V. Shatalov pointed to the fact that many of his students built families. Apparently, during V. Shatalov's lessons, the students had the opportunity to discover and express themselves in the classroom, realize such sides and depths of their personalities that predisposition to love was shaped. Isn't it the delayed result of education? In groups the pedagogue worked with, the boys tended not to have bad habits. As a direct influence of V. Shatalov's pedagogy, the teenagers found other means of self-assertion, such as creativity, autonomy, and active position.

What does the concept of psychological comfort mean? A psychological dictionary gives the following definition of the term "comfort" (English): "a set of features - parameter of workplace estimation, including compliance of each of its individual factors: the physical environment, sensory and motor fields, working position, to the requirements of ergonomics in general. Ergonomics is the science that studies human capabilities in the labor process, identifying opportunities and patterns to create optimal conditions for highly productive labor and provide the necessary facilities, promoting the development of the workers" [5]. Based on the dictionary definitions, and correlating them with psychological concepts, we propose the following definition of psychological comfort in the classroom: a collection of amenities that provide peace of mind, emotional emancipation, create conditions promoting good mental development of the student, the development of his cognitive abilities.

Psychological comfort is necessary to prevent deviations in mental development, correction of neurotic symptoms in children and adolescents, to preserve and strengthen the physical, mental health of the students, as well as to normalize the psychological climate in the team.

It becomes obvious that psychological comfort is an integral part of psychological contact and a necessary condition for its occurrence. Psychological contact promotes the creation of favorable psychological climate in the team. Professor $\mathrm{Z}$. Kalmikova gives the following explanation of the psychological climate in the classroom: "goodwill and mutual understanding between teachers and students, the atmosphere of creativity and interest in the success of each student. It is a quiet, safe, businesslike atmosphere in the classroom, and as a result, the high quality of the knowledge of all students"[6].

Interesting and creative classes, filled with a dose of humor, various activities, meeting the norms of psychological comfort, create such conditions, when students do not get bored, they are not indifferent to the study process, because everybody is involved, each contribution is valued, and everybody benefits. If the teacher lacks creativity, expertise, and desire to develop professionally, his classes become boring, 
monotonous, and as a result, the students lose interest in their studies.

The experience shows that the state of psychological comfort encourages students to be creative, intensifies mental processes, creates best conditions for communication, prepares students to assimilate new information, and opens the pores of consciousness to new knowledge. In this respect each lesson requires a well-designed system of psychological warfare to create a positive emotional background for the correct direction of the process of learning, as emotions affect all components: sensation, perception, imagination, memory and thinking. Emotional setting for the study is an important positive catalyst activity, which contributes to the fruitful work of the organism without excessive tension, providing a situation of psychological comfort. Creation of safe environment and the state of psychological comfort and mutual respect is the main credo of a pedagogue with deontological preparedness.

Educational deontology is the science of the professional duty of a pedagogue, the science of the behavior of a pedagogue in accordance with the professional duty. It develops the regularities and norms of behavior of a pedagogue in the professional sphere. It's a component of the conscious activity and humaneness of a pedagogue. A set of ethical and legal principles and rules, corresponding to a pedagogue's professional duties, refer to pedagogical deontology.

Deontological preparedness is a state of consciousness of the teacher, his knowledge, skills and abilities to perform his duties in accordance with the requirements of teaching ethics. Deontological preparedness is built in the process of deontological training and educating of the future teachers in higher education institutions. In the process of training the following goals are set:

- building the future teachers' awareness of their professional duties;

- forming deontological consciousness of the teacher based on the knowledge of rational norms and principles of pedagogical activity;

- forming deontological self-consciousness through knowledge, humaneness, justice and injustice, duty, honor, and conscience;

- transforming knowledge and selfconsciousness to the faith, belief, and credo.

Convictions and credos regulate the behavior according to the principles of teaching ethics. Conviction is a combination of knowledge and emotions. In pedagogy the knowledge of the social norms and rules of morality, peculiarities of labor in the system "human-human" is an important condition for the teacher compliance with the principles of pedagogical deontology.

We developed the principles of pedagogical deontology based on the postulates of the World Bioethics, adopted at the IV World Congress in Tokyo:

- recognize the autonomy of the individual (personal autonomy), ie the right of every person to decide for himself all the problems related to him, his mental and emotional status;

- follow the principles of justice;

- observe the principle of Hippocrate "Do not harm!";

- in a contemporary bioethics Hippocrate's principle "Do not harm!" is extended to "Not only do not harm, but do good!".

The principles of pedagogical deontology:

1. subdue one's behavior, thoughts, and actions to the principle "Do not harm!" the mental and physical health of the student;

2. make every effort to promote harmonious and nature congruous development of the student;

3. make every effort to eliminate harmful consequences, which have been caused by violation of these principles.

All this contributes to the fact that each teacher learns the skills of self-education and develops personal qualities compatible with pedagogical deontology.

There are no indicators yet to measure changes in health and mental state of the student within one class, student during one class, which would rate the degree of teacher's pedagogical expertise, his deontological preparedness.

There are the following indirect manifestations of the student' states which are the result of the above mentioned factors:

- $\quad$ high quality of knowledge;

- increased activity of students in the study process;

- improvement of the students' overall development level: manifestation of mental emancipation, the ability to clearly express ideas, improving the culture of communication, etc.;

- stabilization of the state of cheerfulness, ingenuity, and wit;

- acquisition of skills of self-assessment and self-control;

- $\quad$ high level of preparedness of the students to continue their education, creative work, and active participation in society for the preservation of morality, physical or psychological health.

Pedagogical Deontology is not an isolated area of human knowledge. It is interrelated with the sciences that study a human being from various perspectives. Pedagogical deontology and philosophy interrelation is traced in determination 
of methodological approaches in forming of deontological readiness of future teacher, in patterns of development of one or another society into various social-economic formations. Such parts of philosophy as dialectics, theory of knowledge promote the development of teacher's research thought as it is one of the indices of deontological readiness.

Pedagogical deontology and pedagogical ethics interrelation is shown up in that fact that pedagogical ethics is the theory basis of pedagogical deontology, as it researches the norms of teacher's professional morals while pedagogical deontology ensures their execution. Both pedagogical deontology and pedagogical ethics focus on the humanization of pedagogical process, but the research area of pedagogical deontology is teacher's professional behavior, his professional-pedagogical morals whereas the research focus of pedagogical ethics is the regularity of morals display in teacher's consciousness, behavior and activity.

The interrelation of these sciences is traced in problems solved by them: whereas pedagogical ethics form the demands made by the society to teacher's moral character, pedagogical deontology investigates the mechanism of introduction of these norms into action; whereas pedagogical ethics form moral value of acts, pedagogical deontology promotes their comprehension and respective regulation of the behavior; whereas pedagogical ethics develop ethical standards of pedagogical activity, pedagogical deontology investigates these norms, rules in actions and acts of workers of education sphere.

Considering pedagogical deontology and psychology interrelation, it is necessary to draw special attention to the problems facing to the given sciences. For example, psychology studies laws of development of the person's mentality, while one of the problems of pedagogical deontology is working out of laws by development of the child's personality on the basis of creation of psychological comfortable atmosphere. The development of children is nothing else but purposeful change of this mentality (thinking, activity). Hence, it can't be carried out by experts without psychological knowledge.

The next aspect of interrelation is at definition of the level of a person's good breeding: good breeding is reflected in motivated acts, system of conscious and impulsive behavior, stereotypes, skills of activity and judgments.

That means that the indicators of progress in teacher's educational work with children are the changes occurring in pupils' mentality and thoughts. In other words, the results of pedagogical activity are diagnosed according to the changes in pupils' psychological characteristics.

The interrelation of these branches of knowledge takes place at use of research methods of pedagogical deontology and psychology. Many tools of psychological scientific search successfully serve to the solution of research problems of pedagogical deontology (a rating, psychological tests, questioning, etc.).

Pedagogical deontology is closely related with physiology. Being a science about the living ability of a complete organism and its separate parts, functional systems, physiology opens the picture of child's material and energetic development.

The laws of functioning of higher nervous activity are especially important for understanding the control mechanism of the child's physical and mental development. The theory of functional systems by P.K.Anohina opens to teacher and learner the nature of the education and socialization processes.

Knowing by teacher the physiological processes of child's and his own development helps to understand the skills of educational influence, prevents from risky, erroneous decisions in the pedagogical work organization, determination of duty as well as in the raising feasible demands to pupils and himself.

Interrelation of pedagogical deontology with sociology is varied. In spite of the fact that sociology is a science about society as a complete system, about making it separate components, about the processes of society functioning and development, owing to its applied character it also studies the education sphere. For example, in the structure of sociological science the following directions, as, education sociology, upbringing, child sociology, health sociology etc. are developed.

The results of sociological research enrich pedagogical deontology and allows to estimate pedagogical phenomena in a perspective of another science. For example, according to sociological researches, among poor schoolboys there are more often males. And subsequently it negatively affects morals, technical progress and defensibility of society. According to sociologists the decrease of the level of compulsory education from an average to incomplete average one on the territory of the former post-Soviet territory has led to multiple increase in offenses, neglect of lives of the minors who have appeared out of school. These and the set of other sociological researches inform teachers about the condition of the system in the social and economic, spiritual, legal and demographic environment.

Essential possibilities of pedagogical deontology development are in prospects of its integration with medicine. To make sure, it is enough to remember the school past. Identical demands of teachers to healthy and unhealthy pupils lead to conflicts and sufferings of the last ones. And didactic gene neuroses caused by experience of educational failures and negative relations between teachers and pupils are particularly dramatic for health of unwell children and teenagers. 
The interrelation of pedagogical deontology with national pedagogy is also important because it helps us to understand and take into account the child's national features of character, to use national traditions and customs in child's education and training, which promote the creation of psychological comfort at the lesson and the correct mutual relations between teacher with all participants of teaching and educational process. Our ancestors didn't read any books but weighing and considering the situations arising in their everyday, usual life, did their best to bring up children decent citizens. For that they transferred across the generations national traditions and customs as an invaluable, precious heritage, which makes positive impact on education and training of growing up generation.

The key condition of Kazakh traditions was upbringing of the person, true to the taken oath, keeping the honor and dignity, clever, judicious etc. All these demands correspond to deontological qualities each teacher should have.

The Kazakh thinkers (Asan Kajgy, Buhar Zhyrau, Shal Akyn, etc.) draw special attention on interrelation and duration of all spheres of human life, foremost material and spiritual riches (Asan Kajgy, Buhar Zhyrau, Aktamberdy etc.), as well as mercy, calmness, human mind (Shalkiiz, Dulat, Murat, Majlykozha, Akan Sery etc.).

The understanding and reservation of public riches left by the previous generations (Makhambet, Shernijaz, Sujenbaj etc.) imposes social and humanistic responsibility on each person. And to transfer it to the future generations is one of the main teacher's professional duties.

Pedagogical Deontology focuses on studying teacher qualifications. Deontological preparedness is considered to be one of the required teacher qualifications. There are several interpretations of the term "deontological preparedness". The most recognized home scholars give the following explanations of the term:

V. Slastenin asserts that the basic component of the structure of teacher's personality is the professional - pedagogical orientation forming "the skeleton round which the basic properties of teacher's personality arrange" [7]. He considers that it is problematic to separate actual pedagogical qualities from other varied features of a teacher's personality, which influence his professional activity. Being a synthesis of varied abilities, qualities of mind, and feelings, these qualities show up, are formed and developed in the general structure of the qualities, relations and actions of the teacher's personality.

N. Nikitina and N. Kislinskaja distinguish two kinds of professional preparedness:

- Teachers' theoretical preparedness, assuming mastering the system of common cultural, general scientific, special, psychological-pedagogical knowledge;
- Teachers' practical preparedness, reflecting the skills, outlined in the job description [8].

M. Djachenko and L. Kandybovich assert that in the course of professional activity not only steady personal features of an individual (beliefs, sights, character traits etc.) are revealed, but also the situational mental conditions connected with the given kind of activity. Preparedness for professional work means the adaptation of an individual's qualities to successful actions in a certain moment [9].

D. N. Uznadze defines the considered concept as a psychological condition of an individual arising for satisfaction of any requirement: "readiness is such an essential sign of a purpose which is shown up in all cases of an individual's behavioral activity" [10].

In the "Dictionary on Social Pedagogy" professional preparedness for any kind of activity is considered as "a subjective condition of an individual considering himself capable and prepared for performance of certain professional work and aspiring to carry it out" [11].

As we see, there are various approaches to research teachers' professional preparedness. There is a set of interpretations of the concept "preparedness for pedagogical activity", which focuses on various aspects of the formation of future teachers' preparedness. Research of teachers' professional preparedness is conducted in several directions:

- Personal approach, considering preparedness as the display of individual-personal qualities caused by character of forthcoming activity (Abulhanova-Slavskaya, Ananiev, Vygotsky, Leontiev, etc.);

- Functional approach, representing it as transient preparedness and working capacity, pre-starting activation of mental functions, ability to mobilize necessary mental resources for activity realization (Ilyin, Levitov, Genov, etc.);

- Personal-active approach, defining preparedness as complete display of all individual's qualities and the ability to carry out functions effectively (A. A.Derkach, M. I. Djachenko, A. I. Mishchenko, and others).

It is significant, however, that in the various interpretations of home and foreign scientists, the concept of deontological preparedness does not consider teachers' preparedness to help students develop their personalities, their physical and mental health, based on the principle "Do no Harm". At the same time it is necessary to note that it is the level of sensible condition of available knowledge, abilities, and skills of the teacher, which are necessary for performance of professional duties in accordance with the deontological principles. The described condition is defined by us as teachers' deontological preparedness (the detailed analysis of educational, scientific-methodical, encyclopedic literature has 
shown us that the term "deontological preparedness" cannot be found in any of philosophical, psychological, pedagogical, and other reference editions).

Deontological competence of a teacher is one of the basic conditions of efficiency of the teaching and learning processes. Deontological preparedness is the state of consciousness, as well as knowledge, abilities, skills, the performance of educational and pedagogical activity in accordance with the professional requirements. It is an integral part of teachers' general preparedness reflecting the level of professional consciousness and comprehension of professional work. In other words, it is an integrative description of a teacher's personality, including scientific-theoretical, methodical and psychological pedagogical preparation, as well as professional abilities and professionally significant qualities of an individual. Hence, the formation of teachers' deontological preparedness is a multi-faceted process.

Teachers' deontological preparedness presupposes not only knowledge of the foundations of Pedagogical Deontology, but also requires active work on realization of its main provisions in various spheres of educational institutions. Teachers' deontological preparedness is a positive professional condition of their consciousness in action (deontological consciousness), which is then transformed into their consciousness. Displays of teachers' consciousness are self-reflective, comprehension of behavior motives, understanding of professional duties. It can be also named as teachers' deontological consciousness.

The matter of teachers' deontological consciousness is constituted by the following purposes :

- Orientation on formation of high pedagogical culture, providing belief in sanctity of the principle "Do no harm to the mental and physical health of a pupil!"

- Orientation to the presence of the increased sense of justice, expressed in the ability to estimate objectively pupils' work and knowledge, in ability to estimate critically their own behavior as well the behavior of others;

- Orientation to the formation of general and special-professional intelligence, learning, an operative awareness not only in the narrow sphere of professional work, but also in adjacent areas of knowledge.

Teacher's deontological preparedness promotes the development of deontological behavior depending on:

- The level of knowledge of foundations of Pedagogical Deontology;

- The degree of professional duty comprehension;

- The specificity of professional work;
- Individual teachers' originality and creativity.

Loss of any of the elements of this system means a teachers' incomplete deontological preparedness.

\section{Conclusion}

Every stage of professional formation of a specialist has its own tasks and objectives, and no matter who is involved - a teacher, a social worker, a psychologist, a coach, or a curator, it is only methods, techniques, and their implementation, that will differ. That includes formation of professional intentions and a conscious selection of a career; productive mastering of social knowledge, skills and abilities and interaction between a trainer and a trainee in the course of education; active introduction to career fundamentals. The stages include the following:

1) formation of professional intentions and a conscious career selection;

2) productive mastering of professional knowledge, skills and abilities;

3) active career introduction;

4) full individual fulfillment to career.

The first stage implies formation of professional intentions and conscious career choice is related to professional orientation which focuses on familiarization of prospective students with job values, significance of job in the modern society, identification of personal peculiarities of prospective students and their professional orientation as a system of emotional and value relations. Effective professional orientation work in schools, colleges, pre-higher education system is of high importance here. This period is very important because it is at the very first stage of professional education where motivation for career choice plays an important role. It is important to define what the person is capable of, what he/she likes to do, and if the right choice has been made, then the objectives of the next stage become more concrete.

The second stage implies mastering of professional knowledge and skill and it will pass more effectively if there is motivation to learning the career.

The third stage - active introduction to a career provides for independent professional and educational activity of students which includes both practical and research activity.

Introduction to a career is a very important stage for a future professional, as practice confirms how much required knowledge and skills a student has, practice allows verification of his/her expectations with the actual professional activity. The final stage is a full individual's fulfillment in a career.

Professional formation of a man is a difficult process, and by going through it a person overcomes difficulties, finds a way out of critical situations of 
age and personal nature and as a result he/she obtains the ability to change his/her own values with support of internal and external environment or he/she is able to render value and spiritual assistance to another person.

Formation of deontological preparedness demands cardinal changes in the teachers' training process. It is necessary to find special ways of perfection of vocational training where formation of teacher's preparedness to perform professional duties becomes one of the most important objectives. This part of educational work is connected with the teachers' outlook, their social, political and humanistic orientations. Teachers of new generation should have the new qualities defining success of their professional work. Hence, there is a necessity of formation of deontological preparedness of all the workers of educational system, beginning with tutors of infant schools, teachers of comprehensive schools, lyceums, colleges, gymnasia, and teachers of higher education institutions.

\section{References}

[1] Okhitina L.T. (1977), Psychological Foundations of the Lesson, "Prosvescheniye", Moscow.

[2] Ozhegov S.I. (1973), Russian Dictionary, Soviet Encyclopedia, Moscow.

[3] M. Rober and F. Tillman (1988), Psychology of an Individual and a Group, Progress, Moscow..

[4] Kan-Kalik V.A. (1990), Training of Professional and Pedagogic Communication/ Methodological recommendations, Moscow.

[5] Dyachenko M.I., Kandibovich L.A (2002), Psychology, Dictionary, Moscow.

[6] Kalmikova Z. (1986), Psychological Research, Moscow.

[7] Slastenin V.A. (1981), Formation of Socio-Active Personality of a Teacher, Sovetskaya Pedagogika, Moscow.

[8] Nikitina N.N. and Kislinskaya N.V., (2004), Introduction to Pedagogical Activity: Theory and Practice, Academia, Moscow.

[9] Kandibovich L.A. and Dyachenko M.I., (1981), Higher Education Psychology, Minsk.

[10] Uznadze D.N. (1986), Psychological Research, Moscow.

[11] Mardakhayev L.V. (2002), Dictionary on Social Pedagogy, Academia, Moscow. 